\title{
EFFICACY OF MULTIPLE ROTARY FILE SYSTEMS IN RETREATMENT OF OVAL-SHAPED ROOT CANALS IN MANDIBULAR MOLARS: A CONE-BEAM COMPUTED TOMOGRAPHY STUDY
}

Hayam Y. Hassan *, Mohamed I. Rabie *, Mohamed M. Ibrahim** and Ahmed M. Negm***

\begin{abstract}
Aim: To evaluate effectiveness of multiple rotary file systems on removal of the filling materials during retreatment of oval-shaped root canals.

Methods: 40 oval root canals were instrumented with ProTaper Next to size X4 (40/.06). The canals were then allocated into two equal groups according to the final rinse, Group I: with Biopure MTAD, and Group II: with 17\% EDTA. All the canals were later obturated with bioceramic based root canal sealer and gutta-percha using cold lateral compaction technique. According to the used retreatment rotary system, each group were further subdivided into two equal subgroups including subgroups Ia \& IIa using D-Race (DR1) (30/.10) + XP-endo Shaper (XPS) (30/.04) + XP-endo Finisher R (XPFR), and subgroups Ib \& IIb using R-Endo retreatment files up to R3 (25/.04) + Revo-S rotary files up to (40/.06). CBCT scans were used to calculate the remaining amount of root filling materials based on a certain threshold given to identify the density of dentin from that of the gutta percha at the pre scan (after obturation), and that of air at the post scan (after retreatment). The dentin volumes were also recorded at both scans to analyze the amount of remaining filling materials.
\end{abstract}

Results: No significant differences were recorded regarding the amount of residual filling material with the tested systems $(p>0.05)$. Intra subgroups assessments showed more filling material removed when using a larger sized final instrument $(\mathrm{p}<0.001)$.

Conclusions: Tested file systems were evenly efficient in removing filling materials from ovalshaped root canals of extracted molars. Types of chelators used and bioceramic based sealer had no significant validity on effectiveness of removal of root canal filling material.

KEYWORDS: Retreatment, Oval-shaped root canals, R-Endo, XP-endo Shaper, XP-endo Finisher R.

\footnotetext{
* Associate Professor of Endodontics, Faculty of Dentistry, Suez Canal University, Ismailia, Egypt. ** Assistant professor of Endodontics, faculty of dentistry, Mansoura University, Mansoura, Egypt. *** Assistant Professor of Endodontics, Faculty of Dentistry, Ahram Canadian University, Giza, Egypt.
} 


\section{INTRODUCTION}

Efficient removal of the root canal filling materials during nonsurgical retreatment-is essential to complement the actions of both the irrigating solutions and the intra-canal medication whenever required. This subsequent improvements in canals' decontamination should eventually contribute to the success of endodontic retreatment ${ }^{(1,2)}$.

Several studies have revealed the challenges encountered when using instruments to remove previous filling materials during non-surgical endodontic retreatment, especially in long oval root canals ${ }^{(3-6)}$. Paqué et al, reported that the prevalence of such oval-shaped canals in the distal roots of mandibular molars is more than $50 \%{ }^{(7)}$, and therefore, additional procedures are required for retreatment of these complicated cases ${ }^{(8-10)}$.

The classical rotary nickel-titanium (NiTi) systems specifically designed for retreatment, like the R-Endo system (Micro-Mega, Besancon, France), were reported to improve removal of the filling materials better than conventional ones ${ }^{(11,12)}$. The expanding XP-endo Finisher and Shaper (FKG Dentaire SA, La Chaux-de-Fonds, Switzerland) are initially designed to improve the cleaning and shaping procedures during conventional root canal treatment. Owing to the special heat treatment during manufacturing, the resulting MaxWire alloy expands at body temperature and allows more adaptation of the file to the canal walls. ${ }^{(13)}$.

Recently, a new modification of the XP-endo Finisher file named XP-endo Finisher R (FKG Dentaire SA, La Chaux-de-Fonds, Switzerland) has been introduced in the market for retreatment cases with a tip size 30 and zero taper, making it more rigid and efficient ${ }^{(14)}$.

One of the prevalently used root canal irrigants is the Biopure MTAD (Dentsply/ Tulsa Dental, Tulsa, OK.). In addition to its reported general antimicrobial ability, it is also known to specifically inhibit the growth of Enterococcus faecalis, which are prevalent in failing cases after nonsurgical endodontic treatment ${ }^{(15)}$. Hassan et al, found that Biopure MTAD also has a powerful chelating effect on removing the smear layer ${ }^{(16)}$.

This Cone-Beam Computed Tomography study is aiming to calculate the residual filling material remaining in oval-shaped distal canals of mandibular molars after retreatment with two different combination protocols of NiTi file rotary systems. The study is also aiming to evaluate the effect of using two different chelating agents commonly used during treatment procedures on the final outcome.

\section{METHODS}

\section{Teeth Selection}

A pool of extracted human mandibular molars were collected. The teeth were imaged with Conebeam computed tomography (CBCT) to ensure the inclusion criteria adopted for this study. A total of 40 mandibular molars were selected, each tooth has a fully formed, single and patent distal root canal with no previous endodontic treatment. On the axial view, the distal root canal was considered oval shaped, when its bucco-lingual maximum diameter measurement at $5 \mathrm{~mm}$ from the root apex was two times larger than its mesio-distal maximum diameter ${ }^{(17)}$.

\section{Preparation of samples}

The 40 chosen samples were serially numbered from 1 up to 40. The preparation procedures were carried out under a magnification of loups (X4, Univet, Italy). Endo-Access burs (Dentsply Maillefer) were used to prepare access cavities using a high speed hand piece. Diamond disks (Kerr Dental, Orange, CA) were used for hemi-sectioning the teeth at the furcation area in order to remove their mesial roots, since the experimental procedures were carried out on the distal roots. \#10 K-file (MicroMega, Besancon, France) was progressed through the root 
canal till it became flushed with the apical foramen, the reference point was adapted at the disto-buccal cusp of the tooth. All measurements were then recorded using a triangular architect's scale ruler and the working length (WL) was calculated by subtracting $0.5 \mathrm{~mm}$.

All canals were serially prepared to the working length using ProTaper Next (PTN) (Maillefer/ Dentsply, Ballaigues, Switzerland) sizes X1(17/.04). X2 (25/.06), X3 (30/.07) and X4 (40/.06). ProTaper Universal SX (Dentsply Maillefer) was initially used to prepare the coronal part of the canal. The files were operated by endodontic motor (X-Smart; Dentsply Maillefer) at $300 \mathrm{rpm}$ and 4-5.2 Ncm with a $16: 1$ reduction handpiece.

A $2.5 \mathrm{~mL}$ of $2.5 \%$ sodium hypochlorite $(\mathrm{NaOCl})$ was used for irrigation after each two successive file sizes. The irrigant was delivered using a plastic syringe with a blunt end side vented 30-gauge needle introduced $2 \mathrm{~mm}$ short of the root length.

\section{Final Irrigation Protocol}

The samples were then randomly allocated into 2 main equal groups of 20 roots each. Group I: 20 root canals received irrigation with Biopure MTAD including a $1 \mathrm{~mL}$ primary immersion for 5 minutes, which was followed by an additional $4 \mathrm{~mL}$ rinse for each canal. Group II: the remaining 20 samples received irrigation with $1 \mathrm{~mL}$ 17\% EDTA (Ethylene diamine tetraacetic acid) (META, BIOMED CO.LTD, Korea.) for at least 3 minutes. Finally, all root canals were rinsed by $2 \mathrm{~mL}$ sterile distilled water to wash out any remnants inside the canals.

Obturation of all root canals was performed with gutta-percha points and Sure-Seal Root ${ }^{\mathrm{TM}}$ (SureEndo, Korea) bioceramic based root canal sealer, supplied in $2 \mathrm{~mL}$ auto-mix syringe. The selected F4 (40/06) (Dentsply/Tulsa; Tulsa, Okla), master cone, was covered with sealer and sited up to the WL. Fine-medium accessory cones (Dentsply Maillefer) were laterally compacted to complete the obturation procedures using standardized \# 25 finger spreaders (Dentsply Maillefer, Ballaigues, Switzerland). The excess gutta-percha cones were cut off at the canals' orifices using heated instrument. All roots were radiographed to confirm the adequate quality of the obturation. The roots were then incubated at $37^{\circ} \mathrm{C}$ and $100 \%$ humidity for at least 7 days to allow complete setting of the sealer.

\section{Preparation of Samples}

All 40 roots were aligned perpendicularly in a custom-made resin models and were dipped in a warm water bath at $36 \pm 1{ }^{\circ} \mathrm{C}$ up to the level of the resin edge to mimic clinical conditions throughout the experiment.

\section{Retreatment Procedures}

Each of the two groups was further subdivided into two subgroups $(n=10)$ each rendering to the type of files used in removal of the root canal filling materials.

\section{Subgroups Ia \& IIa}

The roots were mounted on glass vials used to hold the roots immersed in a warm water bath at a temperature of $37^{\circ} \mathrm{C}$ to mimic physiologic conditions and provide suitable condition for files expantion. The filling materials were removed through creating a start in the coronal portion of the gutta percha (35mm) using D-Race (DR1) (30/.10) (FKG Dentaire SA, La Chaux-deFonds, Switzerland) operating at 800 to $1000 \mathrm{rpm}$ and $1.5 \mathrm{Ncm}$. The tip of an XPendo Shaper file (XPS) (30/.04) was introduced into the prepared space in the gutta percha, disengaged slightly and then the motor was operated at 1000$2500 \mathrm{rpm}$ and $1.0 \mathrm{Ncm}$. A pecking motion was used until the tip of the XPS file engages the gutta percha, then a light pressure was applied to help advancing the file down the canal until the full WL. An additional 10-15 long strokes to the full WL were used to allow the file to gently corkscrew around the gutta percha and remove it out coronally. 
The XP-endo Finisher R (XPFR) was then slowly introduced into the canal to the full working length for at least 1 minute, with the motor (NLZ E S120, NSK, USA) setting at 800-1000 rpm and $1 \mathrm{Ncm}$. This would provide more scrubbing of the canal walls.

\section{Subgroups Ib \& IIb}

The filling materials were removed using the retreatment R-Endo files. R1 file (25/.08) was used at the coronal third whereas the R2 file $(25 / .06)$ was introduced until the beginning of the middle third of the canal. R3 file (25/.04) was then operated until reaching the full WL. The used speed was fixed at $350 \mathrm{rpm}$ and $1.5 \mathrm{~N} / \mathrm{cm}$ torque. Additional canal preparations were carried out using Revo-S rotary files (Micro-Mega, Besancon, France) (30/.06), $(35 / .06)$ and $(40 / .06)$ at speed $300 \mathrm{rpm}$ and $0.8 \mathrm{~N} /$ $\mathrm{cm}$ torque.

The removal process was considered completed once there was no noticeable obturating materials on the file after the instrumentation procedures.

It is imperative here to note that during removal of the obturating material no solvents were used, the canals were irrigated with $2 \mathrm{~mL}$ of $2.5 \% \mathrm{NaOCl}$ with 30-gauge syringes up to $2 \mathrm{~mm}$ short of the WL. All files were used in accordance with the manufacturers' instructions and were discarded after being used in two canals .

\section{CBCT scan}

The next generation iCAT scanner (ISI, USA) was used to scan the perpendicularly aligned roots in their custom-made resin models before and after retreatment.

An initial scouting view was carried out to ensure the correct alignment of the samples, to allow adjusting the light beam before acquisition and finally to ensure that the intended field of view is obtained.

The machine was delivered with $0.5 \mathrm{~mm}$ focal spot size, amorphous silicon flat panel sensor with cesium iodide (CsI) scintillator, 14 Bit gray scale resolution, and operated at the following protocol for all the scans. The tube voltage was $120 \mathrm{kV}$ and the milliampere was $7 \mathrm{~mA}$. The field of view (FOV) had $4 \mathrm{~cm}$ Height and $16 \mathrm{~cm}$ Diameter. The voxel size was $0.125 \mathrm{~mm}$ with a scanning time of 26.9 seconds.

After acquisition, the data were transferred in DICOM format and copied via a Compact Disk (CD) to a personal computer for analysis, where mimics software (version 17; materialize, Belgium) was used for segmenting the teeth separately before and after instrumentation procedures. The volume was calculated based on a certain threshold given to identify the density of dentin from that of gutta percha at the pre scan and that of air at the post scan. The dentin volumes were also recorded at both scans to detect the residual filling material (Figure 1).

The remaining filling material volume $=$ pre scan dentine volume - post scan dentine volume.

Numerical nonparametric data were investigated for normality by checking mean \pm SD. t-test compared concerning two groups in non-correlated samples the significance level was fixed at $\leq 0.0001$. One-way ANOVA supported by Tuckey post-hoc test compared involving more than two groups in non-correlated samples. The significance level was fixed at $\mathrm{P} \leq 0.05$. Statistical analysis was done by IBM ${ }^{\circledR}$ SPSS $®$ Statistics Version 20 for Windows.

\section{RESULTS}

Our results revealed statistically significant differences between the mean dentine volumes of the distal roots before and after retreatment for all subgroups $(\mathrm{P}<0.05)$ as shown in (Table 1$)$.

The mean of the remaining filling materials volume in the root canals was $\left(0.1884 \mathrm{~mm}^{3}\right)$ for (XPS+ XPFR+ MTAD), $\left(0.11834 \mathrm{~mm}^{3}\right)$ for (XPS+ XPFR+ EDTA), $\left(0.11742 \mathrm{~mm}^{3}\right)$ for (R-Endo+ Revo-S+ MTAD) and $\left(0.09486 \mathrm{~mm}^{3}\right)$ for (R-Endo+ Revo-S+ EDTA). These slight differences between subgroups did not reveal any significance $(P>0.0001)$ as shown in (Table 2). 
The percentages of the total filling materials removed after preparations were recorded as $98.05 \%$ for (XPS+XPFR+MTAD), $97.8 \%$ for (XPS+XPFR+ EDTA), $97.48 \%$ for (R-Endo+ Revo-S+ MTAD) and $98.08 \%$ for (R-Endo+ Revo-S+ EDTA). There were no significant differences for these assessments $(P>0.0001)$ as shown in (Table 2$)$.

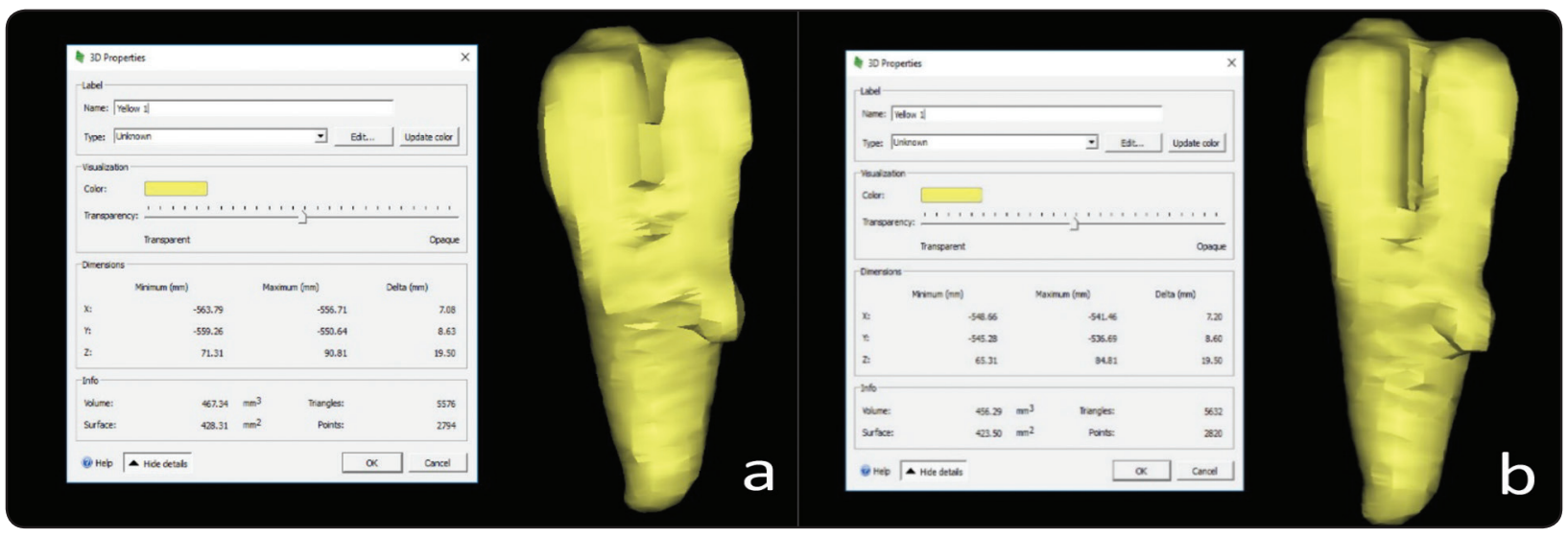

Fig. (1) Dentine volume measurements (a) before and (b) after retreatment.

TABLE (1) Mean dentine volume (mm3) before and after retreatment using two different combination protocols of NiTi file systems.

\begin{tabular}{|l|c|c|c|c|c|c|c|}
\hline \multirow{2}{*}{$\begin{array}{c}\text { NiTi file } \\
\text { systems }\end{array}$} & \multirow{2}{*}{ Final reins } & \multicolumn{2}{|c|}{ Before } & \multicolumn{2}{c|}{ After } & \multirow{2}{*}{ T value } & \multirow{2}{*}{$P$ value } \\
\cline { 3 - 8 } & & Mean & Standard Error & Mean & Standard Error & \\
\hline \multirow{2}{*}{ XPS + XPFR } & MTAD & 5.5790 & 0.29515 & 5.4702 & 0.29616 & -7.755 & $0.0015 * *$ \\
\cline { 2 - 8 } & EDTA & 5.3704 & 0.56296 & 5.2521 & 0.55138 & -5.185 & $0.0066 * *$ \\
\hline \multirow{2}{*}{$\begin{array}{l}\text { REndo }+ \\
\text { RevoS }\end{array}$} & MTAD & 4.6522 & 0.22802 & 4.5348 & 0.22184 & -4.119 & $0.0146 *$ \\
\cline { 2 - 8 }$n$ & EDTA & 4.9492 & 0.22089 & 4.8543 & 0.21517 & -4.093 & $0.0149 *$ \\
\hline
\end{tabular}

${ }^{*}$ Highly statistically significant difference in each row; * Statistically significant difference in each row; $P \leq 0.0001$

TABLE (2) Total mean remaining filling materials and percentage of filling material removal from the root canals after retreatment.

\begin{tabular}{|c|c|c|c|c|c|c|}
\hline NiTi file systems & Final reins & Sub-group & Mean & Mean Removal (\%) & Standard Error & $P$ value \\
\hline \multirow{2}{*}{ XPS + XPFR } & MTAD & Ia & $0.10884^{\text {a }}$ & 98.05 & 0.01403 \\
\cline { 2 - 6 } & EDTA & Ib & $0.11834^{\text {a }}$ & 97.80 & 0.02270 & $0.8744 \mathrm{~ns}$ \\
\hline \multirow{2}{*}{ REndo + RevoS } & MTAD & IIa & $0.11742^{\text {a }}$ & 97.48 & 0.02850 \\
\cline { 2 - 6 } & EDTA & Ilb & $0.09486^{\text {a }}$ & 98.08 & 0.02317 \\
\hline
\end{tabular}

Same superscript lower-case letters indicate a statistically no significant difference
LSD $0.05=0.06807$
$P \leq 0.05$ 


\section{DISCUSSION}

The major aim of this study was to compare the effectiveness of using two different combination protocols of retreatment rotary file systems in ovalshaped root canals. CBCT reconstruction images were used to calculate the amount of the residual filling materials remained adhered to the canal walls.

Root canals with oval shaped cross-sections demonstrate a unique challenge in the distal roots of mandibular molars ${ }^{(18)}$. The current data reveals that the preparation of such canals leaves certain canal surfaces untouched ${ }^{(19,20)}$.

During endodontic retreatment procedures, the filling materials remaining in the canals have been detected by different methods, including longitudinal separation of the roots for microscopic photographic and analysis ${ }^{(21)}$, radiographic imaging (22), and CBCT imaging. CBCT technology provides excellent high-resolution, nondestructive images, which allow accurate quantitative $3 \mathrm{D}$ analysis thus enabling calculations of the percentage of the residual filling materials remained adhered to the canal walls. ${ }^{(23)}$.

The SureSeal Root ${ }^{\mathrm{TM}}$ bioceramic sealer used in obturation of the root canals in this study is known to be osteogenic, biocompatible and hydrophilic. The presence of the smear layer on the root canal walls obstructs the dentinal tubules and thus prevent sealer diffusion into the tubular spaces ${ }^{(24)}$. It was therefore expected that the use of Biopuer MTAD or $17 \%$ EDTA would help eliminating such smear layer and improves the tubular penetration of the root canal sealer ${ }^{(25)}$. Biopuer MTAD eliminate the smear layer by active ingredient of $4.25 \%$ citric acid ${ }^{(25)}$, whereas removal of the smear layer using 17\% EDTA is known to contribute to creating an efficient microretention ${ }^{(26)}$. In this study, neither of the two irrigants used for removing the smear layer during the primary root canal treatment with bioceramic sealer had statistically significant difference regarding the residual volume of filling material in the canals.
In this study, removal of the filling materials was performed by combining more than one rotary file system in the same root canal with a final diameter up to size 40 at the WL. All used file systems performed efficiently in removing the obturating materials.

The reported principal features in estimating the efficacy of endodontic retreatment files are the operator's experience, the file type, using combination of different file systems and the adopted shaping technique ${ }^{(27)}$. One operator with 5 years' experience has performed both the treatment and retreatment procedures.

The D-Race retreatment file system was reported by Özyürek and Demiryürek to have a greater sharpness due to its smooth surface attained by a unique manufacturing electrochemical treatment ${ }^{(28)}$. It also has varying cutting edges which prevent the screwing effect leading to less gutta-percha stuck to the flutes and eventually increasing the cutting efficiency while providing a gliding pathway to the XPS files.

In the present study, the resin model with the roots were immersed in water bath at $36^{\circ} \mathrm{C}$ to simulate the body temperature ${ }^{(29)}$. In accordance with Alfadley et al. ${ }^{(30)}$ the martensitic phase of the XPS file changes to the austenitic phase at body temperature and this will give the file enough rigidity to prepare the entire length of the canal. Silva et al. ${ }^{(31)}$ reported that at body temperature the XPFR file, which has a zero taper and an active tip can follow the canals' morphological changes creating a spoon-like shaped preparation that improves eradicating the residual obturating material in oval-shaped canals.

Garg et al. ${ }^{(32)}$ supported the R-Endo retreatment files that has an active cutting tip, which helps in the initial progression through the gutta-percha and provide adequate cleaning while respecting the canal anatomy. In addition the Revo-S system instruments have asymmetric cross section that induce a snake-like behavior of the file along the canal ${ }^{(33)}$. In this study the final retreatment apical shaping and finishing file had a tip size 0.40 and a 0.06 tapere with a cutting length of $5 \mathrm{~mm}$, as previously conducted by Nasiri and Wrbas ${ }^{(34)}$. 


\section{CONCLUSION}

Following the restriction of this in vitro study, the two different combination protocols of NiTi rotary file systems were equally efficient in eradicating filling materials from oval-shaped root canals of extracted teeth. Further apical enlargement using larger files enhanced the removal of the filling remnants.

\section{ACKNOWLEDGMENTS}

The authors thank Dr. Essam Zaatar, Director Kuwait Board Programs Dentistry at Kuwait Institute for Medical Specialization, for significant review of the manuscript.

The authors contradict any conflicts of interest correlated to this study.

\section{REFERENCES}

1. Borges MMB, Duque JA, Zancan RF, et al. Efficacy of reciprocating systems for removing root filling material plus complementary cleaning methods in flattened canals: Microtomography and scanning electron microscopy study. Microsc Res Tech. 2019; 82:1057-64. https://doi. org/10.1002/jemt.23253.

2. Kasam S, Mariswamy AB. Efficacy of Different Methods for Removing Root Canal Filling Material in Retreatment - An In-vitro Study. J Clin Diagn Res. 2016; 10(6): 6-10. https://doi.org/10.7860/JCDR/2016/17395.7904

3. Rechenberg DK, Paque F. Impact of cross-sectional root canal shape on filled canal volume and remaining root filling material after retreatment. Int Endod J. 2013; 46: 547-55. https://doi.org/10.1111/iej.12027.

4. Vertucci FJ. Root canal anatomy of the human permanent teeth. Oral Surg Oral Med Oral Pathol. 1984; 58, 589-99. https://doi.org/10.1016/0030-4220(84)90085-9

5. Wu M-K, Wesselink PR. A primary observation on the preparation and obturation of oval canals. Int Endod J. 2001; 34, 137-41. https://doi.org/10.1046/j.13652591.2001.00361.x

6. Wu MK, R'oris A, Barkis D, et al. Prevalence and extent of long oval canals in the apical third. Oral Surg Oral Med Oral Pathol Oral Radiol Endod 2000; 89, 739-43. https:// doi.org/10.1067/moe.2000.106344
7. Paqué F, Balmer M, Attin T, et al. Preparation of ovalshaped root canals in mandibular molars using nickel-titanium rotary instruments: a micro-computed tomography study. J Endod. 2010; 36:703-7. https://doi.org/10.1016/j. joen.2009.12.020.

8. Keles A, Arslan H, Aliye Kamalak A, et al. Removal of Filling Materials from Oval-shaped Canals Using Laser Irradiation: A Micro-computed Tomographic Study. J Endod. 2015; 41: 219-24. https://doi.org/10.1016/j. joen.2014.09.026

9. Alves FR, Almeida BM, Neves MA, et al. Disinfecting Oval-shaped Root Canals: Effectiveness of Different Supplementary Approaches. J Endod. 2011, 37: 496-501. https://doi.org/10.1111/j.1365-2591.2012.02045.x

10. Alberto Rubino G, de Miranda Candeiro GT, Gonzales Freire L, et al. Micro-CT Evaluation of Gutta-Percha Removal by Two Retreatment Systems. Iran Endod J. 2018; 13: 221-227. https://doi.org/10.22037/iej.v13i2.18599

11. Tas demir T, Er K, Yildirim T, et al. Efficacy of three rotary $\mathrm{NiTi}$ instruments in removing gutta-percha from root canals. Int Endod J. 2008; 41: 191-6. https://doi.org/10.1111/ j.1365-2591.2007.01335.x

12. Abramovitz I, Relles-Bonar S, Baransi B, et al. The effectiveness of a self-adjusting file to remove residual gutta-percha after retreatment with rotary files. Int Endod J. 2012; 45: 386-92. https://doi.org/10.1111/j.13652591.2011.01988.x

13. Machado AG, Guilherme BPS, Provenzano JC, et al. Effects of preparation with the Self-Adjusting File, TRUShape and XP-endo Shaper systems, and a supplementary step with XP-endo Finisher R on filling material removal during retreatment of mandibular molar canals. Int Endod J. 2019; 52: 709-15. https://doi.org/10.1111/iej.13039

14. Silva E, Belladonna FG, Zuolo AS et al. Effectiveness of XP-endo Finisher and XP-endo Finisher R in removing root filling remnants: a micro-CT study. Int Endod J. 2018; 51: 86 - 91. https://doi.org/10.1111/iej.12788

15. Mohammadi Z, Abbott PV. The properties and applications of chlorhexidine in endodontics. Int Endod J. 2009; 42: 288302. https://doi.org/10.1111/j.1365-2591.2008.01540.x

16. Hassan HY, Negm MM, Abdalla S, et al. Antimicrobial efficiency of Biopure MTAD and sodium hypochlorite as endodontic irrigants. ActaScientific Dent Sci 2020; 4: 1-5. https://doi.org/10.31080/ASDS.2020.04.0787

17. Crozeta BM, Silva-Sousa YT, Leoni GB, Mazzi-Chaves JF, Fantinato T, Baratto-Filho F, Sousa-Neto MD. Micro- 
Computed Tomography Study of Filling Material Removal from Oval-shaped Canals by Using Rotary, Reciprocating, and Adaptive Motion Systems. J Endod. 2016; 42: 793-7. https://doi.org/10.1016/j.joen.2016.02.005.

18. Peters OA, Laib A, Rüegsegger P, Barbakow F. Three-dimensional analysis of root canal geometry by high-resolution computed tomography. J Dent Res. 2000; 79:1405-9. https://doi.org/10.1177/00220345000790060901

19. Siqueira Junior JF, Rôças IDN, Marceliano-Alves MF, et al. Unprepared root canal surface areas: causes, clinical implications, and therapeutic strategies. Braz Oral Res. 2018; 32: 1-18. https://doi.org/10.1590/1807-3107bor-2018. vol32.0065

20. Shah DY, Wadekar SI, Dadpe AM, et al. Canal transportation and centering ability of protaper and self-adjusting file system in long oval canals: An ex-vivo cone-beam computed tomography analysis. J Conserv Dent. 2017; 20:1059. https://dx.doi.org/10.4103\%2F0972-0707.212234

21. Marchi V, Scheire J, Simon S. Retreatment of Root Canals Filled with BioRoot RCS: An In Vitro Experimental Study. J Endod. 2020; 27: S0099-2399(20)30199-0. https://doi. org/10.1016/j.joen.2020.03.018

22. Kfir A, Tsesis I, Yakirevich E, et al. The efficacy of five techniques for removing root filling material: microscopic versus radiographic evaluation. Int Endod J 2012; 45: 35-41. https://doi.org/10.1111/j.1365-2591.2011.01944.x

23. Zameni F, Toursavadkohi S, Afkar M. Comparison of Tubular Penetration of AH26, EasySeal, and SureSeal Root Canal Sealers in Single-Rooted Teeth Using Scanning Electron Microscopy. J Res Dentomaxillofac Sci. 2018; 3:27-32. http://dx.doi.org/10.29252/jrdms.3.3.27

24. Keles A, Alcin H, Kamalak A, et al. Oval-shaped canal retreatment with selfadjusting file: a micro-computed tomography study. Clin Oral Investig 2014; 18: 1147-53. https://doi.org/10.1007/s00784-013-1086-0

25. Hassan HY, Negm AM. A comparative study to evaluate the effect of different irrigating solutions on the smear layer EDJ. 2018; 64: 7-15. https://dx.doi.org/10.21608/edj.2018.78048

26. Patil PH, Gulve MN, Kolhe SJ, et al. Efficacy of new irrigating solution on smear layer removal in apical third of root canal: A scanning electron microscope study. J Conserv Dent. 2018; 21:190-3. https://doi.org/10.4103/JCD. JCD_155_17

27. Faus-Matoses V, Pasarín-Linares C, Faus-Matoses I, et al. Comparison of Obturation Removal Efficiency from Straight Root Canals with ProTaper Gold or Reciproc Blue: A Micro-Computed Tomography Study. J Clin Med. 2020; 9(4):1164. https://doi.org/10.3390/jcm9041164

28. Özyürek T, Demiryürek EÖ. Surface deformation of several nickel-titanium rotary instruments after removal of the root canal filling materials: a scanning electron microscope evaluation. Odontology. 2020; 108: 213-21. https:// doi.org/10.1007/s10266-019-00454-2

29. Bayram HM, Bayram E, Ocak M. et al. Effect of ProTaper gold, self-adjusting file, and XP-endo shaper instruments on dentinal microcrack formation: a micro-computed tomographic study. J Endod. 2017; 43: 1166-9. https://doi. org/10.1016/j.joen.2017.02.005

30. Alfadley A, Alrajhi A, Alissa H, et al. Shaping Ability of XP Endo Shaper File in Curved Root Canal Models. Int J Dent. 2020; 4687045. https://doi.org/10.1155/2020/4687045

31. Silva E, Belladonna FG, Zuolo AS et al. Effectiveness of XP-endo Finisher and XP-endo Finisher R in removing root filling remnants: a micro-CT study. Int Endod J. 2018; 51, 86- 91. https://doi.org/10.1111/iej.12788

32. Garg A, Nagpal A, Shetty S, et al. Comparison of Time Required by D-RaCe, R-Endo and Mtwo Instruments for Retreatment: An in vitro Study. J Clin Diagn Res. 2015; 9:47-9. https://dx.doi.org/10.7860\%2FJCDR\%2F2015\% 2F11100.5596

33. Yeter KY, Evcil MS, Ayranci LB, et al. Weight of apically extruded debris following use of two canal instrumentation techniques and two designs of irrigation needles. Int Endod J. 2013; 46:795-9. https://doi.org/10.1111/iej.12060

34. Nasiri K, Wrbas KT. Comparing the Effect of Reciproc, ProTaper Next and R-Endo in the Removal of Gutta-percha/Sealer and GuttaFlow during Retreatment. Int J Oral Dent Health. 2019; 5:087. https://doi.org/10.23937/2469$5734 / 1510087$ 